This is the peer-reviewed version of the following article:

Nikolić, A. S.; Bosković, M.; Fabian, M.; Bozanic, D. K.; Vucinic-Vasic, M.; Kremenovic, A.;Antić, B. Comparative Structural and Optical Properties of Different Ceria Nanoparticles.Journal of Nanoscience and Nanotechnology 2013, 13 (10), 6787-6792. https://doi.org/10.1166/jnn.2013.7774

All Rights

Reserved

This work is licensed under a Creative Commons - Attribution-Noncommercial-No Derivative $\underline{\text { Works 3.0 Serbia }}$ 


\title{
Comparative Structural and Optical Properties of Different Ceria Nanoparticles
}

\author{
A. S. Nikolic ${ }^{1}$, M. Boskovic ${ }^{2}$, M. Fabian ${ }^{3}$, D. K. Bozanic ${ }^{2}$, M. Vucinic-Vasic², \\ A. Kremenovic ${ }^{2,4}$, and B. Antic ${ }^{2, *}$ \\ ${ }^{1}$ Faculty of Chemistry, University of Belgrade, Studentski trg 12-16, 11000 Belgrade, Serbia \\ 2 The "Vinča" Institute of Nuclear Sciences, University of Belgrade, P.O. Box 522, 11001 Belgrade, Serbia \\ ${ }^{3}$ Institute of Geotechnics, Slovak Academy of Sciences, 04353, Košice, Slovakia \\ ${ }^{4}$ Faculty of Mining and Geology, Laboratory for Crystallography, Djusina 7, 11000 Belgrade, Serbia
}

\begin{abstract}
Herein a comparative study of five nanocrystalline cerium oxides $\left(\mathrm{CeO}_{2-\delta}\right)$ synthesised by different methods and calcined at $500^{\circ} \mathrm{C}$ is reported. XRPD analysis showed that stoichiometry parameter $\delta$, crystallite size/strain and lattice constant were only slightly affected by the method utilized. All ceria nanoparticles are nearly spherical in shape with faceted morphology, free of defects and with a relatively uniform size distribution. The average microstrain was found to be approximately 10 times higher than that of bulk counterpart. The absorption edge of nanocrystalline materials was shifted towards a higher wavelengths (red shift) in comparison with bulk counterpart, and band gap values were in the range 2.7-3.24 eV (3.33 eV for bulk counterpart).
\end{abstract}

Keywords: Ceria, Nanoparticles, Synthesis, Structure, Microstructure, Spectroscopy.

\section{INTRODUCTION}

$\mathrm{CeO}_{2}$ (Ceria) is a technologically important material, especially in nano form. It is widely used as ion conductor in solid oxide fuel cells (SOFCs) ${ }^{1}$ in catalysis, ${ }^{2}$ and for medical purposes. ${ }^{3}$ In addition, thanks to its simple crystal structure, ceria is commonly employed as a modal system for testing of new theoretical models. ${ }^{4}$ A number of experimental studies report on the deviation of $\mathrm{CeO}_{2}$ stoichiometry in nano-sized ceria. Namely, due to creation of oxygen vacancies, a mixed-valence state of cerium $\left(\mathrm{Ce}^{3+}\right.$ and $\mathrm{Ce}^{4+}$ ) exists. Oxygen vacancies (defects) and the ratio of cerium ions with +3 and +4 valences are important for high reactivity of ceria. It is worth mentioning that doping/substitution of ceria has influence on its physical/chemical properties. ${ }^{5,6}$ The substituents can be distributed both at the surface and at the core of the particles. ${ }^{7}$

Ceria crystallizes in the cubic fluorite structure (space group $\mathrm{Fm} 3 \mathrm{~m}$ ). The degree of reduction $\left(\mathrm{Ce}^{4+} \rightarrow \mathrm{Ce}^{3+}\right)$ for small particles (few nm in size) is high or even complete. For small particles (order of a few $\mathrm{nm}$ ) the degree of reduction of cerium $\left(\mathrm{Ce}^{4+} \rightarrow \mathrm{Ce}^{3+}\right)$ is large or the reduction can even be complete. In case of complete reduction a change of stoichiometry and crystal symmetry (from fluorite ceria to $\mathrm{Ce}_{2} \mathrm{O}_{3}$ with space group Ia3) occurs, although

\footnotetext{
${ }^{*}$ Author to whom correspondence should be addressed.
}

some authors have shown that even in the $1 \mathrm{~nm}$ particles the fluorite structure can be preserved. ${ }^{8}$

It is well known that structural and microstructural properties of the material strongly depend on the procedure of synthesis. On the other side, structure/microstructure determines physical/chemical properties (magnetic, electric, optic, catalytic, etc.). Consequently, different synthesis methods for preparation of ceria nano powders were devised. These include sol-gel methods, thermal decomposition of precursors, coprecipitation, solvothermal oxidation, microemulsion methods, electrospray pyrolysis, etc. ${ }^{9}$ In this study, we synthesized nanoscale ceria by different procedures and investigated their structural, microstructural and optical properties after annealing at $500{ }^{\circ} \mathrm{C}$. In addition, we managed to determine the influence of the synthesis procedure on properties of nano-sized ceria.

\section{EXPERIMENTAL DETAILS}

\subsection{Samples Preparation}

First two samples were synthesized by slightly modified procedure described earlier. ${ }^{10}$

Sample $1\left(\mathrm{CeO}_{2-\delta}(1)\right): 3.80 \mathrm{~g}$ of $\left(\mathrm{NH}_{4}\right)_{2} \mathrm{Ce}\left(\mathrm{NO}_{3}\right)_{6}$ (Aldrich) and $2 \mu$ l PEG 200 (Fluka) were dissolved in deionized water. The mixture was continuously stirred while $\mathrm{pH}$ was adjusted to 9 . The solution was transferred 
into a sealed Teflon vessel and placed in microwave source (Milestone, Ethos 1, $2.45 \mathrm{GHz}, 1500 \mathrm{~W}$ ) for 20 minutes at $130{ }^{\circ} \mathrm{C}$ (heating rate $10{ }^{\circ} \mathrm{C} / \mathrm{min}, P_{f} 1.2$ atm). $\mathrm{CeO}_{2}$ powders was washed with deionized water and dried at $80{ }^{\circ} \mathrm{C}$.

Sample $2\left(\mathrm{CeO}_{2-\delta}(2)\right): 6.36 \mathrm{~g}$ of $\left(\mathrm{NH}_{4}\right)_{2} \mathrm{Ce}\left(\mathrm{NO}_{3}\right)_{6}$ (Aldrich) and $46 \mu \mathrm{l}$ PEG 200 (Fluka) were dissolved in deionized water. Subsequently, $\mathrm{NH}_{4} \mathrm{OH}$ (30\%, Merck) was added until $\mathrm{pH}$ value reached 9 . The solution was transferred into a sealed Teflon vessel and placed in microwave source (Milestone, Ethos 1, $2.45 \mathrm{GHz}, 1500 \mathrm{~W}$ ) for 20 minutes at $130{ }^{\circ} \mathrm{C}$ (heating rate $10{ }^{\circ} \mathrm{C} / \mathrm{min}, P_{f} 1.2 \mathrm{~atm}$ ). $\mathrm{CeO}_{2}$ powders was washed with deionized water and dried at $80{ }^{\circ} \mathrm{C}$.

Sample $3\left(\mathrm{CeO}_{2-\delta}(3)\right)$ was synthesized by modified procedure, used for preparing ultrafine ferric oxide. ${ }^{11}$ The $3.29 \mathrm{~g}$ of $\left(\mathrm{NH}_{4}\right)_{2} \mathrm{Ce}\left(\mathrm{NO}_{3}\right)_{6}$ (Aldrich) $(3.29 \mathrm{~g})$ and $27 \mathrm{~g}$ PEG 1550 (Fluka) were dissolved in deionized water. $1.35 \mathrm{~g} \mathrm{KCl}$ (Merck) was added and mixture was efficiently stirred at $70{ }^{\circ} \mathrm{C}$ until sol was formed $(2 \mathrm{~h})$. Obtained sol was dried at $110{ }^{\circ} \mathrm{C}$ for $2 \mathrm{~h}$, and then heated until firing. Obtained powder was suspended into $500 \mathrm{ml}$ of deionized water, filtrated, washed several times with deionized water, and dried at $80^{\circ} \mathrm{C}$.

Samples 4 and 5 were synthesized by simplified standard procedure for preparing various metal-dicarboxylates.

Sample $4\left(\mathrm{CeO}_{2-\delta}(4)\right): 3.18 \mathrm{~g}$ of $\left(\mathrm{NH}_{4}\right)_{2} \mathrm{Ce}\left(\mathrm{NO}_{3}\right)_{6}$ (Aldrich) was dissolved in deionized water. Oxalic acid $\left(1 \mathrm{~mol} / \mathrm{dm}^{3}\right)$ (Merck) has being added until precipitate formed. The precipitate was rinsed with deionized water, filtered, dried, and transferred into a furnace.

Sample $5\left(\mathrm{CeO}_{2-\delta}(5)\right): 3.18 \mathrm{~g}$ of $\left(\mathrm{NH}_{4}\right)_{2} \mathrm{Ce}\left(\mathrm{NO}_{3}\right)_{6}$ (Aldrich) was dissolved in deionized water. Malic acid $\left(1 \mathrm{~mol} / \mathrm{dm}^{3}\right)$ (Merck) has being added until precipitate formed. The precipitate was washed with deionized water, filtered, dried, and transferred into a furnace.

All samples were calcinated at $500{ }^{\circ} \mathrm{C}$ (heating rate $10{ }^{\circ} \mathrm{C} / \mathrm{min}$ ) in air for $4 \mathrm{~h}$.

\subsection{Experimental Methods}

Analysis of particular nano ceria samples with Fourier transform infrared spectroscopy (FTIR) was carried out in order to determine if there were some residues of the reactants on the surfaces of as-prepared samples. Infrared absorbance spectra were obtained using Brucker Tensor 27 spectrometer. The spectra were obtained using 32 scans per sample, with a $4 \mathrm{~cm}^{-1}$ resolution in the $380-4000 \mathrm{~cm}^{-1}$ range. Bulk $\mathrm{CeO}_{2}$ standard was commercial $\mathrm{CeO}_{2}$ (Sigma Aldrich, 99.9\%).

For the collection of the X-ray powder-diffraction (XRPD) data a Brucker D8 advance X-ray powder diffractometer was used. The diffractometer was equipped with a $\mathrm{Cu}$-tube and a Xe-filed proportional counter. The generator was set-up at $34 \mathrm{kV}$ and $20 \mathrm{~mA}$. The divergence and receiving slits were $1^{\circ}$ and $0.1 \mathrm{~mm}$, respectively. The scanning range was $20-110^{\circ}$ in $2 \theta$, with a step of $0.05^{\circ}$ and a scanning time of $40 \mathrm{~s}$ per step.

Transmission electron micrographs and selected-area diffraction patterns were collected with a Jeol JEM 2100 transmission electron microscope operating at $200 \mathrm{kV}$. The samples were prepared by dispersing the powders in acetone and dropping the suspension on a lacey carbon film supported on a 300-mesh copper grid.

The size distribution of the prepared samples was measured by dynamic light scattering (DLS) technique (Nanophox, Sympatec GmbH). Data were evaluated from Brownian motion using 3D Cross Correlation technique. The samples were dispersed in distilled water and treated by ultrasonic bath for five minutes prior the measurement. After that, the samples were placed in the in the temperature-controlled sample holder at least $5 \mathrm{~min}$ before starting the measurement. Light scattering using $\mathrm{HeNe}$ laser $(\lambda=632.8 \mathrm{~nm})$ was set at an angle of $90^{\circ}$ and the temperature was maintained at $25{ }^{\circ} \mathrm{C}$. Second cumulant method of analysis was used to calculate the mean particle size according to the intensity of scattered light.

The UV-vis diffuse reflectance spectroscopy measurements (DR) of the $\mathrm{CeO}_{2-\delta}$ samples were carried out on a Thermo Evolution 600 spectrophotometer equipped with an integrating sphere diffuse reflectance accessory in the wavelength range from $200 \mathrm{~nm}$ to $900 \mathrm{~nm}$.

\section{RESULTS AND DISCUSSION}

\subsection{Samples Formation and Crystal Structure Analysis}

FTIR spectra of ceria samples are shown in Figure 1. Analysis of the FTIR spectra was done based on the results published in literature. ${ }^{12}$ A well defined band due to the stretching frequency of $\mathrm{Ce}-\mathrm{O}$ found at $\sim 413 \mathrm{~cm}^{-1}$, indicates the formation of $\mathrm{CeO}_{2}$. An absorbtion band at $\sim 3438 \mathrm{~cm}^{-1}$ is attributed to the $\mathrm{O}-\mathrm{H}$ stretching vibrations. A band at $\sim 1620 \mathrm{~cm}^{-1}$ is assigned to the $\mathrm{H}-\mathrm{O}-\mathrm{H}$ bending vibrations originating from molecules of water physically adsorbed on the surface of the as-prepared samples. The broadened region in the range of $1300-1600 \mathrm{~cm}^{-1}$ is attributed to the overlapping of the bands characteristic for $\mathrm{NO}_{3}^{-}\left(\sim 1620 \mathrm{~cm}^{-1} 1380 \mathrm{~cm}^{-1}\right.$ and $\left.830 \mathrm{~cm}^{-1}\right)$ and $\mathrm{CO}_{3}^{2-}\left(\sim 1620 \mathrm{~cm}^{-1}, 1054 \mathrm{~cm}^{-1}\right.$ and $\left.851 \mathrm{~cm}^{-1}\right)$ species adsorbed on the surface of $\mathrm{CeO}_{2}$. It is in accordance with the results previously published in the literature. ${ }^{13}$

Crystalline phases in all samples were investigated by XRPD. All reflections in diffraction patterns were indexed on the ceria unit cell in the space group $F m-3 m$ of the fluorite structure. No additional reflections due to any other phase have been noticed. Collected XRPD data were used to refine crystal structure and determine microstructure parameters (crystallite size and strain). Fullprof software package, ${ }^{14}$ in which $\mathrm{TCH}$ Pseudo-Voight function was chosen to describe the profile of diffraction maxima, 


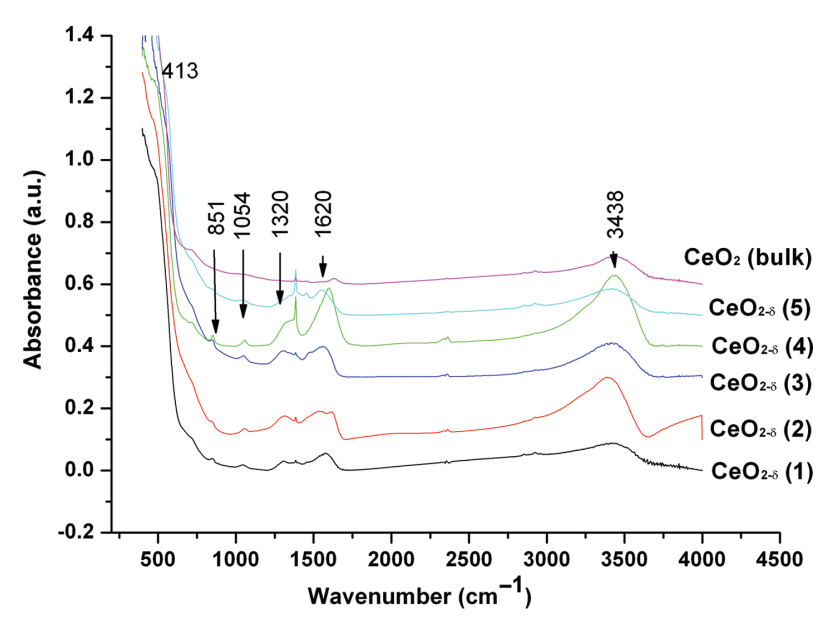

Fig. 1. FTIR spectra of nanosized $\mathrm{CeO}_{2-\delta}$ and bulk counterpart.

was used in order to resolve the microstructure parameters (crystallite size and microstrain). Size of the crystals and microstrain are microstructural effects responsible for the profile shape of the diffraction peaks. XRPD pattern
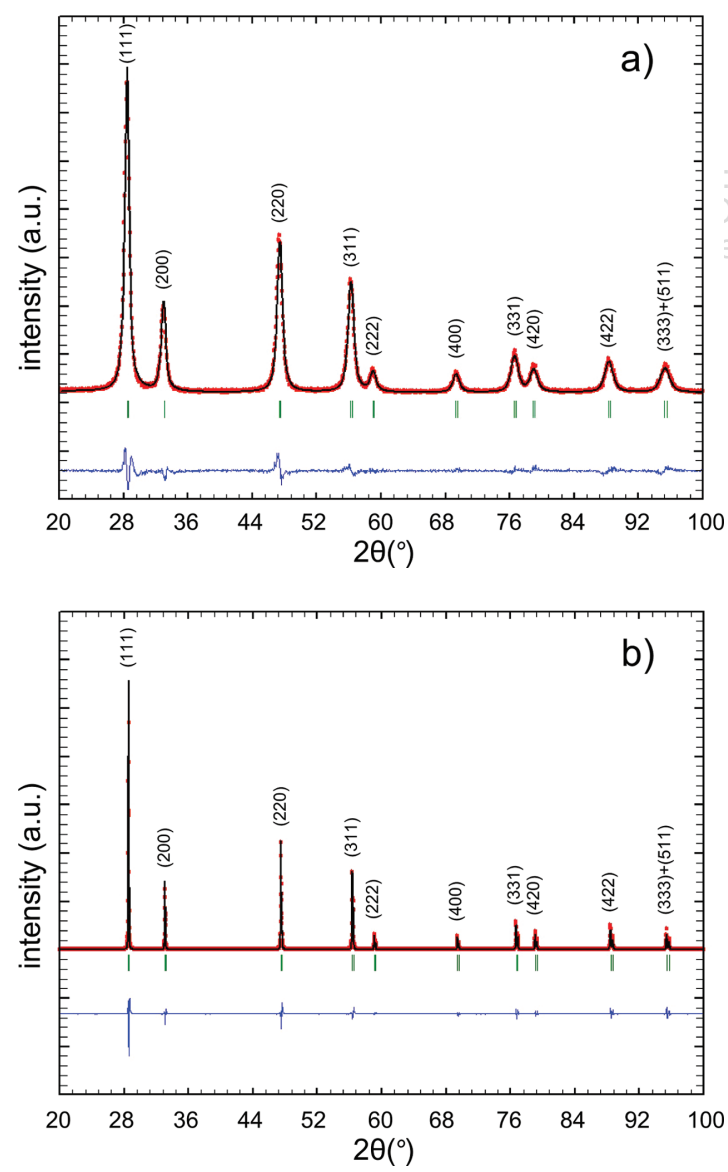

Fig. 2. Final Rietveld plots for nanosized $\mathrm{CeO}_{2-\delta}$ (1) (a) and bulk counterpart (b). Dots denote observed step intensities; the line represents the corresponding calculated values. The difference curve between observed and calculated intensities is given at the bottom. Vertical lines correspond to reflection positions.
Table I. Lattice parameter, average crystallite size, average microstrain and non-stoichiometry parameter $\delta$ of $\mathrm{CeO}_{2-\delta}$ determined by Rietveld method.

\begin{tabular}{lcccc}
\hline Sample & $a(\AA)$ & $\begin{array}{c}\text { Average } \\
\text { crystallite } \\
\text { size }(\mathrm{nm})\end{array}$ & $\begin{array}{c}\text { Average } \\
\text { microstrain } \\
\left(10^{-4}\right)\end{array}$ & $\begin{array}{c}\text { Non- } \\
\text { stoichiometry } \\
\text { parameter } \delta\end{array}$ \\
\hline 1 & $5.4209(1)$ & 10 & 33 & 0.017 \\
2 & $5.4197(1)$ & 8 & 50 & 0.015 \\
3 & $5.4186(1)$ & 12 & 40 & 0.013 \\
4 & $5.4191(1)$ & 8 & 45 & 0.014 \\
5 & $5.4197(1)$ & 10 & 30 & 0.015 \\
Bulk counterpart & $5.4112(1)$ & - & 4 & 0 \\
\hline
\end{tabular}

of a standard $\mathrm{LaB}_{6}$ was used to make a correction for the instrumental broadening. Figure 2 shows the final Rietveld plots for $\mathrm{CeO}_{2-\delta}(1)$ and $\mathrm{CeO}_{2}$ (bulk). Final Rietveld plots for other specimens are omitted due to their similarity with the plots presented in Figure 2. Determined structural and microstructural parameters are presented in Table I.

It is well known that partial reduction of $\mathrm{Ce}^{4+}$ to $\mathrm{Ce}^{3+}$ ions occurs in ceria nanoparticles; this induces creation of oxygen vacancies and deviation from $\mathrm{CeO}_{2}$ stoichiometry. ${ }^{1,9}$ The oxygen vacancies influence local disordering and affect values of lattice parameters. Values of refined lattice parameters for ceria samples are presented in Table I. These values are little bit different, but notable higher than that for the bulk sample. Namely, due to the difference between ionic radii of $\mathrm{Ce}^{3+}(1.034 \AA)$ and $\mathrm{Ce}^{4+}$ $(0.92 \AA)$, the ratio $\mathrm{Ce}^{3+} / \mathrm{Ce}^{4+}$ impacts values of lattice parameters in ceria nanoparticles. Deviation of stoichiometry (i.e., parameter $\delta$ in $\mathrm{CeO}_{2-\delta}$ ) can be determined by using refined values of lattice parameter listed in Table I and applying Hong and Virkar empirical formulae: ${ }^{15}$

$$
a(\mathrm{~nm})=0.54113(\mathrm{~nm})+\delta \times 10^{-2}(\mathrm{~nm})
$$

The $\delta$ was calculated to be in the range $0.015-0.017$. Isotropic crystallite size and microstrain were calculated using joint crystal structure Rietveld refinement and sizestrain analysis in Fullprof program. The results are presented in Table I point out significant number of structural imperfections in nanoparticles.

\subsection{Particle Size and Agglomeration}

The particle size and morphology of the samples were characterized by transmission electron microscopy. The typical HRTEM images of $\mathrm{CeO}_{2-\delta}$ are shown in Figure 3. HRTEM analysis reveals that the particles are isotropic, with a relatively uniform size distribution. It can be seen that the particle size depends on the method of synthesis: it was $\sim 8 \mathrm{~nm}$ for samples 1,2 and $4, \sim 10-15 \mathrm{~nm}$ for sample 3 and $\sim 12-15 \mathrm{~nm}$ for sample 5 . These results combined with those obtained by XRPD analysis show that, in average, one particle is composed of one or two crystallites. Further HRTEM analysis enabled us to clarify 

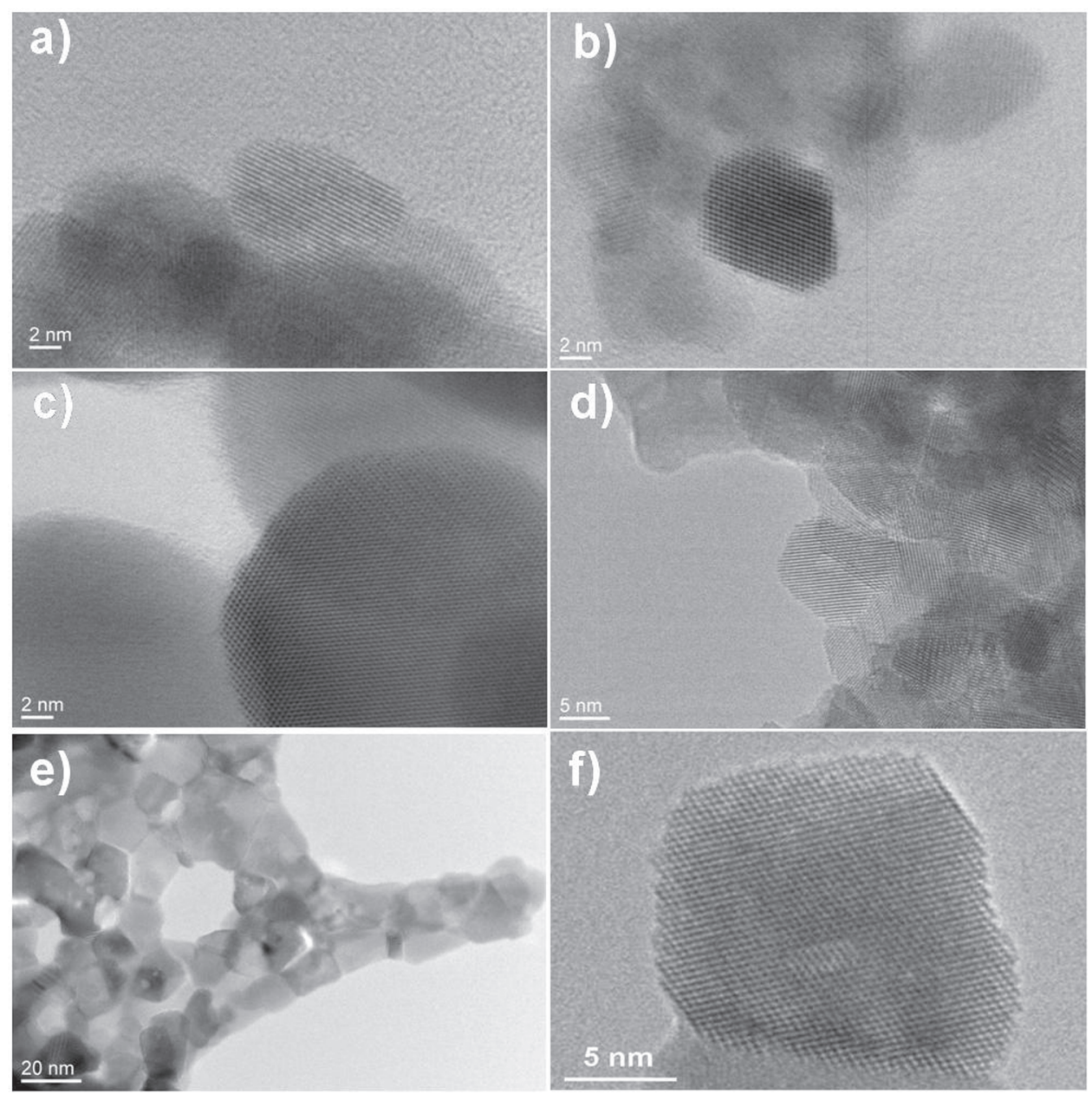

Fig. 3. HRTEM images of $\mathrm{CeO}_{2-\delta}$ obtained by different synthesis routes (see text): (a) $\mathrm{CeO}_{2-\delta}$ (1), (b) $\mathrm{CeO}_{2-\delta}$ (2), (c) $\mathrm{CeO}_{2-\delta}$ (3), (d) $\mathrm{CeO}_{2-\delta}$ (4), (e) $\mathrm{CeO}_{2-\delta}$ (5), (f) $\mathrm{CeO}_{2-\delta}$ (5).

the morphology of the synthesized particles. The particles are nearly spherical in shape with faceted morphology. A detailed analysis of particle surface showed the absence of the amorphous shell (see e.g., Figs. 3(a)-(c), (f)). Morphology of nanoparticles is important feature that influences their catalytic efficiency. Size effects on the physical properties of ceria was shown in literature. For example, electrical conductivity was enhanced for almost $40 \%$ with the increase of the average grain size. ${ }^{16}$

The DLS measurements were performed in order to analyze agglomeration in our samples. DLS assumes that particles (agglomerates) have a spherical shape. The results obtained for particle diameters are in fact equivalent sphere diameters. Obtained particle size distribution curves are shown on Figure 4. Clusters (agglomerates) with average hydrodynamic diameters ranging from 230 to $310 \mathrm{~nm}$ was noted, The smallest agglomerates were present in the sample $\mathrm{CeO}_{2-\delta}(5)$. The results of DLS measurement showed that the abundance of the fraction of agglomerates smaller than $100 \mathrm{~nm}$ was negligible for all samples as well as that agglomerates greater than $700 \mathrm{~nm}$ do exist. These agglomerates consist of many monocrystalline or polycrystalline particles because their hydrodynamic diameters were at least one order of magnitude larger than average crystallite size obtained from XRPD and mean particle size

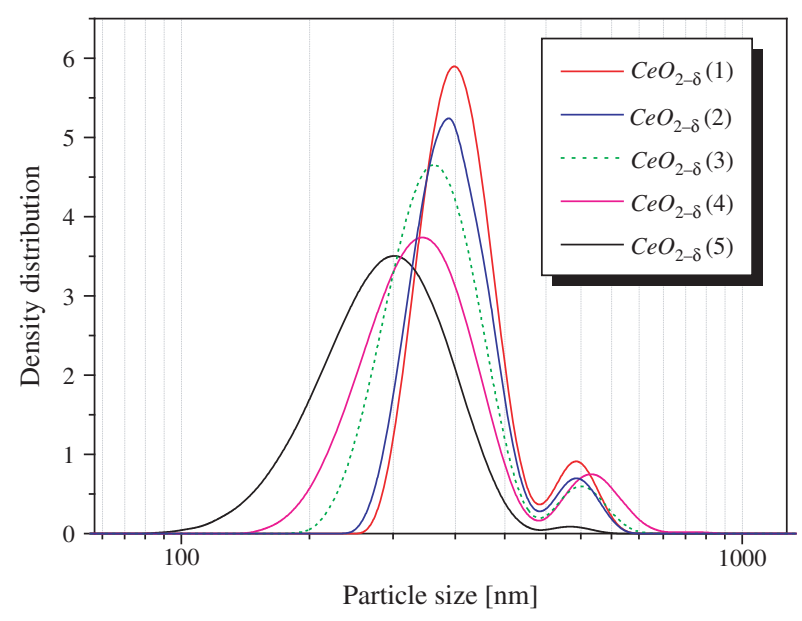

Fig. 4. Particle size distribution for samples $\mathrm{CeO}_{2-\delta}(1)-\mathrm{CeO}_{2-\delta}$ (5). 
obtained from HRTEM. All samples show certain level of bimodality which is the most pronounced for sample $\mathrm{CeO}_{2-\delta}(4)$, as can be seen in Figure 4. The position of the second peak at particle size distribution curves ranged from 500 to $540 \mathrm{~nm}$.

\subsection{UV-Vis Diffuse Reflectance Spectra}

One of the main applications of ceria is in catalysis. Its catalytic activity depends on optical properties, particularly on bandgap. ${ }^{17}$ The bandgap of investigated samples and for their bulk counterpart were determined using UV-Vis spectrophotometry. The UV-visible reflectance spectra of the $\mathrm{CeO}_{2-\delta}$ nanoparticles synthesized by different routes were measured, and then, the absorption, $F(R)$, was calculated according to Kubelka-Munk equation,

$$
F(R)=\frac{\left(1-R^{2}\right)}{2 R}
$$

where $R$ is the reflectance of the sample. Results of this transformation are shown in Figure 5. The spectra of all samples show strong absorption bands below $400 \mathrm{~nm}$ due to the charge-transfer transition from $\mathrm{O}^{2-}(2 \mathrm{p})$ to $\mathrm{Ce}^{4+}(4 \mathrm{f}) .{ }^{18}$ Optical band gap can be determined using Tauc relation

$$
F(R) h \nu=C\left(E_{g}-h \nu\right)^{n}
$$

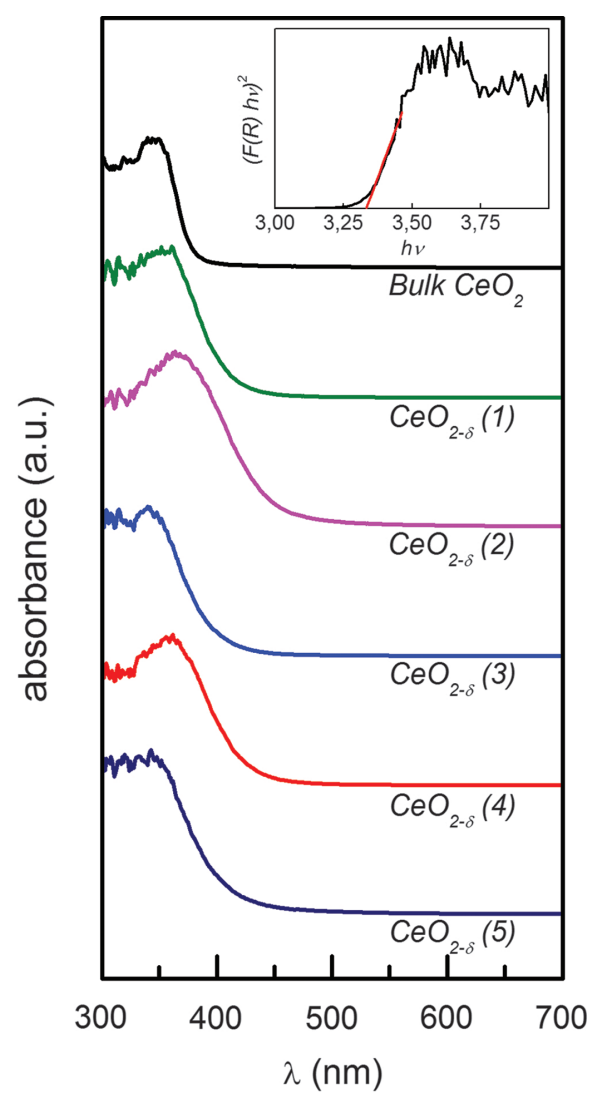

Fig. 5. Absorbance curves of $\mathrm{CeO}_{2-\delta}$ nanoparticles synthesized by different procedures (main panel) and plot of the $(F(R) h \nu)^{2}$ versus photon energy for determination of optical band gap (inset). where $h \nu$ is the photon energy, $n$ is $1 / 2$ for direct transition and 2 for indirect, $E_{g}$ is the bandgap and $C$ is a constant. ${ }^{19}$ Value of the direct bandgap is then estimated by extrapolating linear portion of the curve $(F(R) h \nu)^{2}$ versus $h \nu$ to a point where absorption $F(R)$ is equal to zero (the inset of Fig. 5). For samples from $\mathrm{CeO}_{2-\delta}(1)$ through $\mathrm{CeO}_{2-\delta}(5)$ the following values were determined: $3.13 \mathrm{eV}, 2.90 \mathrm{eV}$, $3.24 \mathrm{eV}, 3.06 \mathrm{eV}$ and $3.16 \mathrm{eV}$. The value of bandgap for bulk counterpart was $3.33 \mathrm{eV}$, so all nanoparticle samples show red shift in their absorption edge. The red shift is due to formation of localized states within the band gap due to the well-known intrinsic defect chemistry $\left(\mathrm{Ce}^{3+}\right.$ and $\mathrm{O}^{2-}$ vacancy concentration) of ceria in the fluorite structure. ${ }^{20}$ This is in accordance with earlier conclusion that all samples show some level of deviation from stoichiometry (Table I). The other reasons for different values in bandgap among nano ceria are probably be due to difference in types of imperfections on the particle surfaces.

\section{CONCLUSIONS}

Cerium dioxide has been prepared by different methods of synthesis and characterised by various techniques. The synthesis method influences to stoichiometry, lattice parameters as well as microstructure parameters (crystallite size and strain). By each of the applied methods particles with spherical morphology were produced. From UV-visible reflectance spectra bandgap value was calculated. Differences in determined values were induced by structural imperfections both at particles core and surface. Partial reduction of cerium ions with the creation of oxygen vacancies results in introducing intermediate energy levels and consequently smaller values of the gap.

Acknowledgment: The Serbian Ministry of Education and Science supported this work financially through the projects Grants Nos. III45015 and 172035. We would like to thank to Dr. Bostjan Jancar for performing HRTEM measurements. M. Fabian expresses his gratitude to APVV (project No. 0189-10) for support of his work.

\section{References and Notes}

1. M. Mogensen, N. M. Sammes, and G. A. Tompsett, Solid State Ionics 129, 63 (2000).

2. R. Rangel, G. J. López Mercado, P. Bartolo-Pérez, and R. García Sci. Adv. Mater. 4, 573 (2012).

3. D. Schubert, R. Dargusch, J. Raitano, and S.-W. Chan, Biochem. Biophys. Res. Co. 342, 86 (2006).

4. M. Leoni, R. Di Maggio, S. Polizzi, and P. Scardi, J. Am. Ceram. Soc. 87, 1133 (2004).

5. R. Li, C. Li, S. Yin, C. Fu, and T. Sato, J. Nanosci. Nanotechnol. 12, 2797 (2012).

6. M. I. Nandasiri, R. Sanghavi, S. Kuchibhatla, and S. Thevuthasan, Nanosci. Nanotechnol. Lett. 4, 7954 (2012).

7. S. J. Shih, Y. J. Yu, and Y. Y. Wu, J. Nanosci. Nanotechnol. 12, 7954 (2012). 
8. R. K. Hailstone, A. G. DiFrancesco, J. G. Leong, T. D. Allston, and K. J. Reed, J. Phys. Chem. C 113, 15155 (2009).

9. Y. Ju-Nam and J. R. Lead, Sci. Total Environ. 400, 396 (2008), and references therein.

10. M. L. Dos Santos, R. C. Lima, C. S. Riccardi, R. L. Tranquilin, P. R. Bueno, J. A. Varela, and E. Longo, Mater. Lett. 62, 4509 (2008).

11. J. Song, Z. Y. Ma, C. Li, and R. J. Wu, J. Inorg. Mater. 25, 780 (2010).

12. F. A. Miller and C. H. Wilkins, Anal. Chem. 24, 1253 (1952).

13. N. Audebrand, N. Guillou, J. P. Auffredic, and D. Louer, Thermochim. Acta 286, 83 (1996).
14. J. Rodriguez-Carvajal, FullProf.2k (Version 2.40-May 2003-LLB JRC) Computer program; www-llb.cea.fr/fullweb/fp2k/fp2k.htm.

15. S. J. Hong and A. V. Virkar, J. Am. Ceram. Soc. 78, 433 (1995).

16. I. Solodkyi, H. Borodianska, Y.Sakka, and O. Vasylkiv, J. Nanosci. Nanotechnol. 12, 1871 (2012).

17. Y. S. Chaudhary, S. Panigrahi, S. Nayak, B. Satpati, S. Bhattacharjee, and N. Kulkarni, J. Mater. Chem. 20, 2381 (2010).

18. B. Choudhury and A. Choudhury, Mater. Chem. Phys. 131, 666 (2012).

19. S. Phoka, P. Laokul, E. Swatsitang, V. Promarak, S. Seraphin, and S. Maensiri, Mater. Chem. Phys. 115, 423 (2009).

20. B. Tatar, E. D. Sam, K. Kutlu, and M. Ürgen, J. Mater. Sci. 43, 5102 (2008).

Received: 9 March 2013. Revised/Accepted: 11 April 2013. 